\title{
Synthesis and Bioactivity Studies of Some Naphthoquinone Derivatives as Potential Proteasome Inhibitors ${ }^{+}$
}

\author{
Şirin Uysal ${ }^{1}$, Zeynep Soyer ${ }^{1, *}$, Recep İlhan ${ }^{2}$ and Petek BALLAR Kirmizibayrak ${ }^{2}$ \\ 1 Department of Pharmaceutical Chemistry, Faculty of Pharmacy, Ege University, 35100 Bornova/İzmir, \\ Turkey; sirin.uysal@gmail.com \\ 2 Department of Biochemistry, Faculty of Pharmacy, Ege University, 35100 Bornova/İzmir, Turkey; \\ recep.ilhan@ege.edu.tr (R.İ.); petek.ballar@ege.edu.tr (P.B.K.) \\ * Correspondence: zeynep.soyer@ege.edu.tr \\ + Presented at the 2nd Molecules Medicinal Chemistry Symposium (MMCS): Facing Novel Challenges in \\ Drug Discovery, Barcelona, Spain, 15-17 May 2019.
}

Published: 12 November 2019

The ubiquitine-proteasome pathway (UPP) plays a major role in protein degradation in eukaryotic cells. It has been shown that this pathway is involved in many physiologically critical cellular processes. As the main component of the UPP, the 26S proteasome unit is responsible for the degradation of polyubiquitinated proteins and has multicatalytic proteinase activities. Increased levels of this enzyme have been implicated in many disorders, including inflammation, neurodegenerative, immune diseases, and cancer. Thus, the development of proteasome inhibitors has emerged as an attractive target for the treatment of these diseases, especially cancer [1]. Bortezomib, Ixazomib, and Carfilzomib have been approved by the US Food and Drug Administration (FDA) for the treatment of multiple myeloma. Despite the remarkable success of these inhibitors in the clinic, they have several shortcomings. Therefore, there is still a need to develop new and selective proteasome inhibitors [2]. The compound named PI-083, bearing naphthoquinone group, has recently been reported as a proteasome inhibitor. It has been shown that PI-083 has a broader antitumor activity and is more selective against cancer cells compared to Bortezomib [3]. On the basis of these findings, using a PI-083 lead compound, we designed and synthesized some sulfonamide and carboxamide derivatives bearing naphthoquinone pharmacophoric group as potential proteasome inhibitors and then evaluated their cytotoxic and proteasome inhibitory activities on a human breast cancer cell line (MCF-7). According to the biological activity results, the compounds showed cytotoxic activity at various ratios, and the sulfonamide derivative bearing 2chloro-3-pyridyl group on amide nitrogen exhibited significant proteasome chymotripsin-like activity inhibition compared to the lead compound PI-083.

Acknowledgments: This work was supported by The Scientific and Technological Research Council of Turkey (TÜBITAK) (Project ID:116S300).

\section{References}

1. Kisselev, A.F.; Goldberg, A.L. Proteasome inhibitors: from research tools to drug candidates. Chem. Boil. 2001, 8, 739-758. 
2. Adams, J.; Kauffman, M. Development of the Proteasome Inhibitor Velcade ${ }^{\mathrm{TM}}$ (Bortezomib). Cancer Invest. 2004, 22, 304-311.

3. Kazi, A.; Lawrence, H.; Guida, W.C.; McLaughlin, M.L.; Springett, G.M.; Berndt, N.; Yip, R.M.L.; Sebti, S.M. Discovery of a novel proteasome inhibitor selective for cancer cells over non-transformed cells. Cell Cycle 2009, 8, 1940-1951.

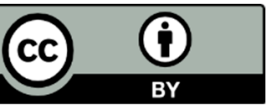

(C) 2019 by the authors. Licensee MDPI, Basel, Switzerland. This article is an open access article distributed under the terms and conditions of the Creative Commons Attribution (CC BY) license (http://creativecommons.org/licenses/by/4.0/). 